\title{
Research on the Application of Flipped Classroom Teaching Mode in the Course of Mechanical Drawing
}

\author{
Runqin He \\ Ningbo University of Finance \& Economics, Zhejiang Ningbo 315175, China \\ keenhsy@126.com
}

\begin{abstract}
Based on the "mechanical drawing " course, the construction of the flipped classroom teaching model, the overall planning of the curriculum design, the teaching design is complete and implement. The research method of comparative experimental analysis, and analyzed the effects of learning. Practice shows that the flipped classroom teaching model can promote students' autonomous learning ability and sustainable learning ability.
\end{abstract}

Keywords: flipped classroom, mechanical drawing, teaching design.

\section{Introduction}

Mechanical drawing is a basic course for electromechanical majors to study the drawing and reading rules of mechanical drawings. In current teaching, theoretical courses are mainly taught by teachers, mainly teaching related content of mechanical drawing. Theoretical basis of the research.

The Flipped Classroom concept is derived from Jon Bergmann and Aaron Sams, two chemistry teachers at woodland park high school in rocky mountain, Colorado [1].In 2011, flipped classroom became a research hotspot, gradually became familiar to many teachers, and became a new teaching mode concerned by the global education circle, which was attributed to khan academy founded by salman khan, which produced thousands of teaching video by computer for online learning [2].

Many scholars at home and abroad have done a lot of theoretical research on flipped classroom teaching model. For example, Robert Talbert of franklin college in the United States summarized the implementation structure model of flipped classroom after years of experience in flipped classroom teaching model [3]. By analyzing the origin, concept and characteristics of flipped classroom, Jinlei Zhang, Ying Wang and others built the flipped classroom teaching model on the basis of case studies of foreign teaching practices, and analyzed the challenges faced in the implementation of flipped classroom, with a view to providing reference for the teaching reform in China [4]. In addition, many teachers have made theoretical research and reform practice of flipped classroom teaching model [5-8]. With the development of information technology and the constant updating of teaching concepts, flipped classroom has become a research hotspot in the education field.

Flipped Classroom, or "Inverted Classroom," is the idea of rearranging time in and out of the Classroom so that decisions about learning shift from teachers to students. Students use after-class time to learn new knowledge through online courses and video, and digest and apply the knowledge through class discussion.

\section{Teaching Model Creation and Curriculum Overall Planning}

\subsection{Establishment of Teaching Model}

American scholar Gerstein[9] was the first to construct the flipped classroom teaching model in 2011, dividing the classroom into four stages: experiential learning stage, concept exploration stage, meaning construction stage and demonstration and application stage. Subsequently, with the global popularity of flipped classroom, many scholars at home and abroad have built a variety of flipped classroom teaching frameworks. According to the nature of the course and the learning characteristics of students, and by referring to the experience of scholars at home and abroad, we created the model based on flipped classroom teaching mode: before class, in class and after class.

In this model, the whole learning process is divided into three stages: knowledge transfer, knowledge internalization and knowledge recovery. In the knowledge transfer stage, video is 
carefully selected or recorded according to the learning characteristics of students, and the teaching information of each video is clear and concise, forming a series of micro-classes. And through the pre-class exercises to grasp the students' learning level, at the same time, teachers open online tutoring. In the stage of knowledge internalization, the role of teachers is transformed from the traditional lecture to the leading role, and students are transformed from the supporting role to the leading role. The tasks presented in class can be provided by students and teachers in both directions, and the solution of the tasks is mainly accomplished through group discussion. The knowledge remediation stage can be achieved by re-watching video and doing after-class exercises. Through the flipped classroom teaching mode of "learning-teaching-practice", the knowledge points of the course are digested and absorbed.

\subsection{Overall Curriculum Planning}

\subsubsection{Course Introduction}

"Mechanical drawing" course in our university are divided into drawing foundation (I), professional graphics (II), computer graphics (III) three parts, three consecutive semester teaching. Since the beginning of the course, we have also carried out relevant teaching reform, such as project teaching, case teaching and so on. However, in terms of teaching methods, the traditional teaching method of "teaching-learning" is basically adopted. Classroom teaching is mainly taught by teachers and students do homework after class. Lack of inspiration and autonomy in learning makes students' problem-solving ability, independent thinking ability and teamwork ability not explored.

\subsubsection{Class Planning}

After the establishment of the teaching model, class hour planning should be carried out according to the teaching outline, and the content suitable for flipping should be selected to try, so as to avoid falling into the vicious circle of "flipping for the sake of flipping".

\subsubsection{Assessment Method}

In terms of assessment methods, the current exam-oriented final examination, which lacks the cultivation of students' knowledge application, scientific thinking and innovative ability, should be changed to set up a process assessment mode based on the embodiment of knowledge, ability and quality. Integration of course content, the curriculum evaluation in accordance with section or module, according to the nature of chapters content to take a written test, homework and examination form of computer operation, as each phase of the written test scores, and then combine classroom performance, team mutual (including group evaluation and group evaluation), usually get students in this stage. According to the different importance of the content of each chapter or module in the knowledge and ability assessment of the course, the weights of each chapter are set to get the final scores of students.

\section{The Teaching Design}

According to the constructed based on the reverse of the classroom teaching model, the mechanical drawing III courses, for example, design and implementation of the whole teaching process. First is the analysis of learning, the teaching object as a sophomore, before this has been learning "mechanical drawing" I, II and computer basic courses, have knowledge chart, hand drawing and computer operation ability, most students learning attitude, have a thirst for knowledge. The number of students in the class is 50 . The students are divided into 8 groups. Each group is equipped with a leader with strong sense of responsibility. Then, a detailed design is made before, during and after class.

\subsection{Before Class}

For teachers, teaching resources should be prepared before class, which can be referred to books, electronic materials and moocs, or self-made micro-courses. As the existing resources on the Internet are not strong targeted, direct use of inappropriate. Therefore, the production of micro-course is the core content in the preparation of teaching resources. According to the teaching objectives of each class, the knowledge points can be broken down, and 1-5 micro-lessons can be recorded. Each micro- 
lesson introduces 1-2 knowledge points, and the time is no more than 10 minutes. After the production, upload the micro class to QQ, WeChat, or the network disk, and let students download and learn by themselves. And send out the task list one week in advance.

For students, they should carefully check the task list issued by the teacher and complete the requirements of the task list. The tasks assigned by the task list should have optional tasks, so that students with ability can choose. In the process of learning, I can record the problems existing in my self-study, summarize them by the group leader and feed back to the teacher.

\subsection{In Class}

Classroom teaching is generally divided into three links: basic knowledge learning, knowledge acquisition and acceptance, and summary.

\subsubsection{Basic Knowledge Learning}

Students explain

According to the previous self-study content, representatives from groups 2-4 are selected to explain the operation mode of pre-class homework or command. During the explanation, members from the same group can supplement, while members from other groups can question. Each group should be controlled within 5 minutes.

Teacher summarize

After each group is finished, the teacher makes a supplement according to the difficulties.

\subsubsection{Knowledge of Acceptance}

Teachers assign exercises in class and discuss in groups.

Each group presents its own results, and the others correct mistakes and ask questions. If there are different methods can be discussed again, the teacher to guide.

\subsubsection{Summarize}

Make a summary of the main content of this lesson. Help students to consolidate the knowledge of this lesson,Deep understanding of students. Assign homework and make mutual evaluation.

\subsection{After Class}

After class, you can break through the knotty knowledge points by reviewing video and doing exercises.

\section{Learning Performance Analysis}

\subsection{Experimental Methods}

The implementation of this curriculum reform adopts the method of comparative experiment between two classes of the same grade and the same major. First of two classes of "mechanical drawing" I, II and basic computer, this paper compares and analyzes three classes of the final exam found for "mechanical drawing" course I, materials have failed in the 12, not all materials to pass the exam, other materials to two courses is also a difference in the materials. This fully indicates that before applying flipped classroom teaching mode, the comprehensive level of pilot class has no advantage compared with that of parallel class. In view of the three modules of plane graphics, part drawings and assembly drawings in this course, the pilot class adopts the flipped classroom teaching mode, and the assessment method is stage assessment. The module of plane graphics and part drawings adopts the in-class test, and the module of assembly drawings adopts the method of large homework + work report. The parallel class adopts the traditional teaching mode of teacher teaching + student practice, and the assessment method is the in-class test, which focuses on the part drawing module. 


\subsection{Comparison of Test Results}

Although the assessment methods of the two classes are different, the pilot class not only examines the mastery of knowledge, but also examines the application of knowledge. However, for the convenience of comparative analysis, the content of the final assessment of the parallel class is completely consistent with that of the stage assessment 2 of the pilot class. The ranking statistics of the test scores of these two classes were conducted from high to low, and the ranking chart of the test scores of students in figure 1 was obtained.

As can be seen from the figure, the test scores of the pilot class are better than those of the parallel class. The average score of the parallel class is 71.4 , while that of the pilot class is 79 , with an average difference of about 8 points.

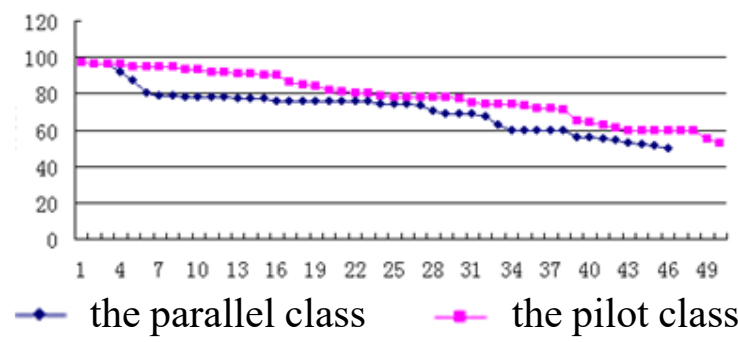

Fig.1 Ranking chart of scores

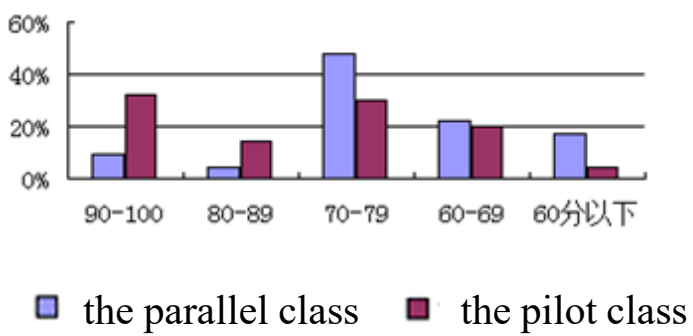

Fig .2 Distribution chart of scores

Then, the scores of the two classes were analyzed by using the column graph, and the statistical graph of the distribution of scores was shown in figure 2. As can be seen from the figure, the distribution proportion of students in parallel classes in these five grades is $9 \%, 4 \%, 48 \%, 22 \%$ and $17 \%$ respectively. The proportion of students in the pilot class in these four achievement sections is $32 \%, 14 \%, 30 \%, 20 \%$ and $4 \%$, respectively. The excellent rate of the pilot class is $23 \%$ higher than that of the parallel class, which is much higher than the parallel class, which fully demonstrates the superiority of flipped classroom teaching mode.

\section{Conclusion}

Flipped classroom is not so much an innovation of teaching mode as an innovation of teachers' teaching concept. It is not a subversion of traditional lecturing teaching mode, but rather a supplement of lecturing teaching mode. We can completely combine the two modes as teaching practice and carry out extensive application practice. , of course, in the reform practice, flip on classroom still exist some problems which solve, such as control of the situation of students' learning before class, group members to play soy sauce phenomenon, and due to the large number of lead to take care of all the members in the situation, and so on, in the subsequent teaching practice, all of these will be our problem.

\section{Acknowledgements}

This work was Supported by Central Audiovisual Education Center of China (No. 176130019).

\section{References}

[1]. Information on: http:// educationnext.org/the-flipped-classroom.html.

[2]. Information on: http://baike.baidu.com/view/5913590.htm.

[3]. Information on: http://prezi.com/dz0rbkpy6tam/inverting-the-linear -algebra-classroom.

[4]. Jinlei Zhang, YiWang. Introducing a New Teaching Modle. Classroom. Journal of Distance Education.2012 (3). p.14-16. 
[5]. WANG Hong, ZHAO Wei1, The Design of Flipped Classroom Teaching Model-Analysis Based on Typical Cases at Home and Abroad. Modern Educational Technology,2013(3). p.5-10.

[6]. Xinglong Zhao. The Design of Teaching Mode Based on Knowledge Construction in Flipped Classroom. Modern Distance Education Research.2014, p.55-61.

[7]. Fulton, Kathleen. The Flipped Classroom: Transforming Education at Byron High School, T H E Journal,2012(39). p46.

[8]. Herreid, Clyde Freeman. Case Study: Case Studies and the Flipped Classroom [J]. Journal of College Science Teaching, 2013(39). p62.

[9]. Information on: http://www.scoop.it/t/the-flipped-classroom . 